\section{Effects on health of mustard gas}

SIR - Graham S. Pearson, in his review of Veterans at Risk: The Health Effects of Mustard Gas and Lewisite ${ }^{l}$ dismisses suggestions that US veterans exposed to small amounts (2 drops) of mustard gas on the skin should be identified. He points out that, in the tests, one drop of mustard gas was removed immediately with a decontaminant and the second two minutes later.

Because a long-term health risk has not been identified, Peason asks, why should those who took part in the tests be worried by being contacted at this stage? The 4,000 US servicemen exposed to higher concentrations of chemical warfare agents are, as Pearson says, the ones most at risk, and, given the dearth of information on the effect of poison gas on human beings, this cohort must be the one to follow in the first instance.

Mortality records of British and US servicemen exposed to mustard gas suggest an increased incidence of lung cancer $^{2}$, although smoking was a confounding factor in the British study. Chronic bronchitis was also increased among UK veterans exposed to mustard gas, but this, too, is difficult to evaluate because of uncertainty about smoking habits ${ }^{3}$. Civilians involved in the manufacture of mustard gas have a high incidence of lung cancer and respiratory cancer in general ${ }^{4}$.

It may now be too late to confirm whether lung or respiratory cancer is increased in servicemen exposed to mustard gas on the battlefield; the First World War was the last conflict in which troops were caught either without, or with inappropriate, gas masks. The exceptions, of course, are the Iranians injured by mustard gas between 1983 and 1988 in the Iran-Iraq war; many of them had ill-fitting masks. Kurdish civilians in Iraq had no masks at all when they were gassed in 1988.

There is also the outstanding question about the long-term effects of exposure to nerve agents. It is known that Britain's Chemical Defence Establishment at Porton Down carried out studies to develop a prophylactic treatment against nerve gas (and against the agent soman in particular). Porton's work on the prophylactic could be a real life-saver. Conventional treatments for dealing with other organophosphate nerve agents are much less effective against soman.

Porton's studies were said to involve 300 men consuming tablets of the carbamate pyridostigmine bromide followed by exposure to the organophosphate nerve agent sarin. Total exposure would (in theory) inhibit 60 per cent of acetylcholinesterase activity in serum, whereas in practice the combined treatments resulted in about a 50 per inhibition ${ }^{5}$. It is the inhibition of this enzyme at the neuroacute symptoms in those poisoned by organophosphates.

There are outstanding questions about the long-term health effects of acute (and chronic) exposure to both organophosphates and pyridostigmine. Porton's 'volunteers' might prove to be a useful group to follow up for some answers. There is documented evidence of exposure, blood chemistry and, presumably, a register that could be used to trace individuals.

\section{Alastair Hay}

Department of Chemical Pathology, Old Medical School,

University of Leeds,

Leeds LS2 9JT, UK

1. Nature 365. 218 (1993).

2. IARC Monographs 9, 181-192 (1975).

3. Case, R. A. M. \& Lee, M. J. Brit. J.Prev. Soc. Med. 9 62-72 (1955),

4. Wada, S. etal. Lancet. 1, 1161-1163(1968)

5. Gall, D. Fundam. Appl. Toxicol 1. 214-216 (1981).

SIR - Graham S. Pearson, who is associated with the Chemical and Biological Defence Establishment at Porton Down, complains that the Institute of Medicine (IOM)'s study committee included no members from the US Department of Defense (DOD) and only a few members of the IOM or National Academy of Sciences (NAS). But the policy of the IOM and NAS is to appoint committee members on the basis of expertise; the inclusion of four IOM members and one NAS member is not unusual; some committees have more, some fewer. It is also policy to exclude individuals who, by their relationship with specific government agencies, may have conflicts of interest on the subject of a study. That disqualified members of the armed services or employees of the DOD from serving on the committee, but the views of such individuals were sought (and are detailed in Appendix A of the report). The committee was also given a presentation by a person who had been actively involved in chemical testing programmes during the Second World War.

Pearson accuses the committee of ignoring the standards of the time and forgetting that chemical warfare was a reasonable expectation in the Second World War. But the committee did consider this question, but could not ignore clear evidence of abuse. For example, Chapter 4 says that the committee "believes that the... investigators inhood of great numbers of gas casualties". Yet the responsibilities of physicians then and now are to "do no harm". Even War Department permissions to use servicemen in these experiments included that muscular junction that causes many of the volved. . . were convinced of the likeli- condition, yet many were injured from exposures equivalent to First World War gas attacks.

The treatment of the "volunteers" was documented in the IOM report by examination of the military's experimental records. This treatment included outright threats if subjects refused repeated gas chamber trials, sometimes despite the presence of symptoms of gas poisoning described by military physicians before the Second World War. One could argue that wartime exigencies should modulate judgement of these tactics, but (as the report documents) such practices were continued by the military in the United States well into the 1970 s. Also, although the Nuremberg Code did not emerge until after the war, a central thrust of the trials that produced the code was that its basic principles governed conduct before and during the war.

From incomplete records, the IOM committee knew of at least (rather than only) 4,000 servicemen involved in the high-exposure chamber and field tests. The military historian Rexmond Cochrane (cited in the report) reported 60,000 total participants in chamber, field and patch tests. The committee's recommendations regarding illnesses such as lung cancer and emphysema clearly stated that these would occur only in chamber and field-test participants, not among those only exposed in patch tests. The US Department of Veterans Affairs, however, accepts skin cancer in the scars of patch-test participants as causally related to mustard gas.

Pearson states that this committee's standards would argue for "compensation" of nonsmoking military personnel or students in chemistry laboratories for the effects of passive smoking and benzene despite the fact that the effects of these substances were not known at the time. This analogy is inappropriate, because military research, some published in open scientific literature before the Second World War, documented long-term health effects in gas victims from the First World War - chiefly bronchitis, emphysema, chronic asthma, corneal opacities and keratitis. The records show that no attempts were made by the military to warn the subjects of the possibility of these debilitating effects. In fact, the subjects were forbidden on threat of prosecution to discuss their experiences, even with their personal physicians. That oath of secrecy was finally lifted on 10 March 1993. In the report's recommendations, the term "compensation" is never used. Rather, the Departments of Defense and of Veterans Affairs were asked to try to find affected veterans still living and to evaluate and treat medical problems caused by the exposures they received.

Finally, Pearson accuses the committee of unreasonably raising "alarm and anxie- 
ty" among US servicemen and their families. A full reading of the report would show that the committee struggled with this idea throughout. Differences in exposure levels between the test types were explained in detail and an expert in risk communication was consulted in an attempt to reduce potential anxieties and fears. These efforts were balanced against the desire voiced by veterans to know what had happened to them and to end decades-long doubts about the causes of their health problems. The committee clearly states that not all the veterans' questions could be answered on the basis of rigorous scientific analysis. Yet, the veterans who have contacted the committee (now well over the 250 cited in the report) seem most grateful that their experience, so long ignored and denied, was finally affirmed.

\section{David P. Rall}

(Committee Chair)

Constance M. Pechura

(Study Director)

Institute of Medicine (FO3036),

2101 Constitution Avenue, NW,

Washington, DC 20418, USA

\section{Fidia and neuroscience}

SIR - In the press coverage concerning the falterings of the Fidia Pharmaceutical Corporation in Italy (Nature 364, 562; 1993 ) and the financial fall-out threatening the viability of the Fidia Georgetown Institute for the Neurosciences (FGIN), the most important dimension seems to have been overlooked.

Lost somewhere between enumerations of broken promises and legal battles are the significant human resources that define the FGIN. This institute, under the directorship of Professor Erminio Costa, is comprised of our fellow faculty and scientific colleagues, who, since the institute's inception in 1985, have dramatically enriched the intellectual and academic environment at Georgetown University. The invaluable contributions of these eminent scientists should not be reduced to a price tag or a percentage of a budget.

As faculty members of various departments at Georgetown, we have benefited in many ways from our collaboration with members of FGIN. This special relationship has attracted students and faculty. The research conducted by this group has enhanced our research programmes and resulted in the initiation of several new projects funded by the National Institutes of Health. FGIN has trained students and scientists from less wealthy countries, inspiring us to follow suit. Dollars cannot measure what we have gained by the growth and development of the FGIN in our midst. Nor can money mea- sure what we stand to lose if this group of neuroscientists is not given the support and encouragement necessary for them to continue at our university.

\section{Karen Gale}

on behalf of 33 members of the faculty Georgetown University Medical Center. 3900 Reservoir Road NW,

Washington, DC 20007-2195, USA

SIR - Your brief account of the troubles of the Italian pharmaceutical company Fidia was unfair with respect to the support it has given to basic neuroscience. I do not wish to defend the actions of the Italian government, and clearly Fidia Pharmaceuticals has made managerial mistakes for which they are paying, but to refer to the Fidia-sponsored programme of scientific conferences, travel grants, prizes to established and young scientists, training of postdoctoral fellows (as in my case) and the establishment of laboratories in Washington DC as "eyebrow-raising largesse" and worse still "a rat to be smelled out" is not nice. Indeed Fidia has spent more money (as percentage of turnover) on research and development than any other European pharmaceutical company, largely supporting basic research (see Nature 361, 765-768; 1993). Fidia's fall-out should be seen with sadness rather than derision.

\section{Stefano Casalotti}

Neuro-behaviouralBiology Center,

Mahidol University, Salaya,

Nakorn Pathom 73170.

Thailand

SIR - We are concerned that your article may give the impression that, following a lawsuit by Georgetown University against Fidia over a reimbursement due in 1995 for the construction of a research building, the university has decided to retaliate by closing the Institute of Neuroscience (FGIN). We believe that such a move would greatly damage relations between universities and industry.

Although your report states that FGIN represents only 10 per cent of Georgetown's spending on neuroscience, the importance and impact of the contributions made by FGIN dwarf any other results that the university may have obtained with the remaining 90 per cent of neuroscience research spending. One might conclude that the size of investment does not always guarantee the quality of science, but it is the latter that counts.

The FGIN achievements have been assessed by an ad hoc committee selected last year by the university to carry out a periodical in-depth review of the institute's scientific activities. The committee, consisting of A. J. Aguayo (president), S. F. Heinemann, K. Fuke, H. Mohler and E. M. Johnson, prepared a positive and laudatory report. Moreover, in a survey in Nature of industry-sponsored activities in
US universities (361, 765-768; 1993) the institute's activities were evaluated positively. Surprisingly, your article states that FGIN will not survive, which contrasts with a report on the same topic that appeared almost simultaneously in The Lancet $(\mathbf{1 4}, 625 ; 1993)$.

The report of the peer-review committee on FGIN includes a list of 232 papers from FGIN published in peer-reviewed journals during its eight-year existence. There is evidence for impressive training activities (18 PhDs, 56 postdocs). Moreover, 25 scientists have spent sabbatical leaves at the institute.

We do not believe that your statements on FGIN's future reflects the thinking of the university leadership in view of the scientific and monetary benefits the university has received from FGIN. In our view, your leading article damages the scientific image of an institute that includes highly respected neuroscientists.

Giorgio Bernardi (President, Italian Society of Neuroscience); Giovani Biggio (Chairman, Department of Experimental Biology, University of Cagliari); Vittorio Erspamer (Professor Emeritus of Pharmacology, University of Rome); Walter Fratta (Chairman, Department of Neuroscience, University of Cagliari); Gian Luigi Gessa (Professor of Neuropsychopharmacology, University of Cagliari); Paolo Mantegazza (Rector, University of Milan); Flavio Moroni Professor of Pharmacology, University of Florence); Giancarlo Pepeu (Chairman, Department of Pharmacology, University of Florence)

- In August, a spokesperson for Georgetown University said that the future of the FidiaGeorgetown Institute for Neuroscience was "questionable" if, as was considered likely, Fidia failed to honour its contract to help pay for its promised $\$ 30$ million share of the cost of new premises for the institute. The spokesperson says that the outlook has improved since then, and that "a new version of the institute may be constituted" when the financial reorganization of Fidia in Italy is complete. - Editor, Nature.

\section{No need to write}

SIR - Hermann Bondi (Nature 365, 484; 1993) deduces by a clear and simple argument that "the human mind is singularly liable to be mistaken on religious issues", and observes that "the variety of religions is a calamitously divisive force in human affairs". To anybody brought up in Northern Ireland, this conclusion and observation have been so self-evident that we had never (previously) realized that it merited a letter to Nature. Res ipsa loquitur.

Mark Cantley

131 rue Verbiot.

B-1030 Brussels, Belgium 